\title{
ESR Dosimetric Properties of Sodium Glutamate
}

\section{S. Eid, S. Ebraheem and A. Sobhy}

Radiation Protection and Dosimetery, Dept., National Centre for Radiation Research and Technology (NCRRT). P. O. Box; Nasr City, Egypt.

\begin{abstract}
$\mathrm{M}$ ONO SODIUM GLUTAMATE powder and rods $(3 \mathrm{x} 10$ $\mathrm{mm}$ ) were studied to be a radiation sensitive material for ESR dosimetry. Samples were irradiated with ${ }^{60} \mathrm{Co} \gamma$ - rays. The developed signal after irradiation increases with the increase of the mono sodium glutamate in the rods. The prepared powder can be used in the dose range from (10-90) $\mathrm{kGy}$, whereas the rods are useful in the range from (10-120) kGy. The obtained number of free radicals per $100 \mathrm{ev}$ ( $\mathrm{G}$ value) was found to be $0.201 \pm 0.01$. The $\mathrm{g}$ factor is $2.0113 \pm 0.0001$. The rods have the advantage of negligible humidity effects during irradiation. The pre and post irradiation stability was found to be satisfactory.

Keywords: Mono sodium glutamate, Electron paramagnetic resonance, Radiation dosimetry.
\end{abstract}

Ionising radiation (gamma rays form ${ }^{60} \mathrm{Co}$ and ${ }^{137} \mathrm{Cs}$ sources, $\mathrm{x}$-ray and electron beam) has been used for a long time in order to sterilize medical devices to improve hygienic quality of food (Gancheva et al., 2006) or for sterilization of drugs and cosmetics (Regulla and Deffner, 1983 and Talbi et al., 2004). Electron paramagnetic resonance (EPR) was proposed as a method to measure radiation induced radicals. One of the advantages of EPR dosimetry is that the readout does not affect the spin concentration; the sample can be evaluated many times. Therefore, the signal to noise ratio $(\mathrm{S} / \mathrm{N})$ can be improved by repeated reading of the sample (IKeya, 1993). The Application of EPR to radiation dosimetry yields several materials such as tissue equivalent alanine, which is convenient for use in transfer dosimetry at high and intermediate dose. Efforts to use EPR dosimetry in health physics have resulted in a minimum detectable dose of 10mGy (Nakajima, 1988, Nakajima, 1995 and Nakajima et al 1990). Lithium lactate was used to measure the low dose from 0.1 to $10 \mathrm{~Gy}$ by applying a modulation field of 0.25 $\mathrm{mT}$ and using a sharp signal of $\mathrm{g}=2.0035$ (Hassan and Ikeya, 1997). A high modulation field of $1 \mathrm{mtT}$ was used to measure intermediate and high dose by using the quartet signal of Li-lactate (Hassan et al., 1998). 
A number of solid materials, including amino acids, in which free radical populations are formed by irradiation, have been suggested for high dose dosimetry by EPR analysis. A useful method of high dose measured is the use of ESR spectroscopy of irradiated amino acids, in particular L-alanin, $\mathrm{CH} 3 \mathrm{CH}(\mathrm{NH} 2) . \mathrm{COOH}$ purified in polycrystalline form (Bermann et al., 1970, Beshir et al., 2012, Bradshow et al., 1962 and Regulla and Deffner, 1982). Poly (methylmetacrilate)-maghemite (PMMA-gamma-Fe2O3) hybrid material was studied by the electron stimulated ion desorption techniques coupled with timeof-flight mass spectrometry (TOF/MS) and theoretical investigation about its fragmentation were carried out (Rocha et al., 2014). The objective of the present study is preparation of a new EPR routine dosimeter by simple technique in the laboratory by mixing mono sodium glutamate with both vinyl acetate co-polymer and paraffin wax. The radiation induced radical in glutamate powder and rods were investigated from dosimetric point of view.

\section{Experimental}

\section{Materials}

Mono sodium glutamate $\mathrm{H}_{2} \mathrm{O}$ with molecular formula $\mathrm{C}_{5} \mathrm{H}_{8} \mathrm{NNaO}_{4} . \mathrm{H}_{2} \mathrm{O}$. M. wt 187.13 , melting point $232^{\circ} \mathrm{C}$, water solubility $\geq 10 \mathrm{~g} / 100 \mathrm{ml}$ at $200{ }^{\circ} \mathrm{C}$ as well as melt stick adhesive based on ethylene vinyl acetate copolymer (TecBond32/12, Power Adhesives Limited, England) and paraffin wax (congealing point $\left.65-71^{\circ} \mathrm{C}, \mathrm{BHD}\right)$ were selected as binding materials for mono sodium glutamate rod preparation. This binder was previously selected in preparation of alanine/EPR rods $(3 \mathrm{x} 10 \mathrm{~mm}$ ) for high dose radiation dosimetry in the range 1-125 kGy (Abdel-Fattah et al., 2004).

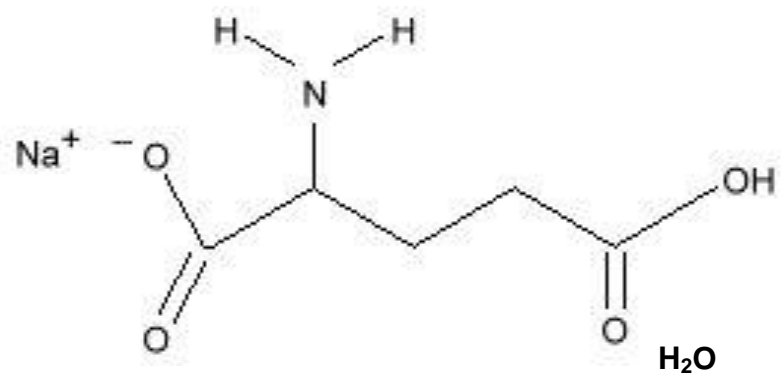

Fig.1. Structure formula of monosodium glutamate.

Egypt. J. Rad. Sci. Applic., Vol. 27, No. 1-2 (2014) 


\section{Preparation of mono sodium glutamate rods}

An equal weight mixture of paraffin wax and Ethylene Vinyl acetate (EVA) co-polymer was melt at $85-95^{\circ} \mathrm{C}$ in a water bath 5, 10, 20 and $40 \%$ fine powdered mono sodium glutamate was added to the hot mixture solution and completely mixed by mechanical stirrer for about $15 \mathrm{~min}$ at the same temperature to obtain homogeneous mixture and then sucked into polypropylene tubes (inner diameter $3 \mathrm{~mm}$ ) and was left to solidify by cooling. Mono sodium glutamate mixture rod was obtained by removing the poly propylene tube then cut into rods $(3 \mathrm{x} 10 \mathrm{~mm})$ the average mass of prepared rods was found $0.08 \mathrm{~g} \pm 0.002$. It was found that, the use of EVA/paraffin as a binder did not show any interference or noise in the EPR signal before and after irradiation by our investigation.

\section{Irradiation of the prepared sample}

${ }^{60} \mathrm{Co}$ irradiation facility was used for Irradiation of the powder and the prepared rods. The absorbed dose rate was about $3.0639 \mathrm{kGy} / \mathrm{h}$ overall the time of the experimental part. Three rods of monosodium glutamate for each dose point were irradiated together at the central position of gamma cell using a specially designed holder made from polystyrene to ensure electronic equilibrium. Samples were irradiated at various absorbed doses from (10-120 $\mathrm{kGy}$ ) to establish the response curve.

\section{EPR measurements}

EPR spectra of unirradiated and irradiated mono sodium glutamate were recorded at ambient temperature with a Bruker EMX spectrometer (X-band); product of Bruker, Germany the cavity used was the standered Bruker ER 4102 rectangular cavity. The operating conditions for the EPR spectrometer were as follow: microwave frequency: $9070 \mathrm{GHz}$; microwave power $0.796 \mathrm{mV}$; modulation frequency $100 \mathrm{kHz}$; modulation amplitude 5 Gauss; time constant: $81.92 \mathrm{~ms}$; sweep time: $20.97 \mathrm{~s} / \mathrm{scan}$. The bottom of the EPR tube was adjusted at a fixed position to ensure reproducible and accurate positioning of the rods in the sensing zone of the cavity to obtain higher reproducibility and accuracy of the EPR results. The intensity of each irradiated rod dosimeter was recorded at two orientations in the EPR cavity $\left(0^{\circ}\right.$ and $\left.90^{\circ}\right)$ by changing the position of EPR tube in the cavity. In addition, all of $\mathrm{SH}$ reading was corrected to $\mathrm{SH}$ of the reference standard material $\left(\mathrm{SH}_{\mathrm{r}}\right)$ of 2, 2- diphenyl-1-picrylhydrazyl (DPPH).

Egypt. J. Rad. Sci. Applic., Vol. 27, No. 1-2 (2014) 
The DPPH was measured before and after each series of measurements in the same rectangle cavity at the same identical measurement conditions in order to correct for change in the spectrophotometer sensitivity. After that, the dose response curve was established in terms of $\left(\mathrm{SH}_{\mathrm{s}}\right)$ divided by sample wt corrected by $\left(\mathrm{SH}_{\mathrm{r}}\right)$ as a function of absorbed dose, where corrected $\mathrm{SH}=\mathrm{SH}_{\mathrm{s}} / \mathrm{SH}_{\mathrm{r}} \mathrm{x}$ wt).

\section{Results and Discussion}

\section{Spectral features}

Fig. 2. shows the EPR spectrum of irradiated mono sodium glutamate powder, shows sextet signal with $g$ factor $2.0325 \pm 0.0013$ for $S_{1}, 2.02188 \pm$ 0.0019 for $S_{2}, 2.01135 \pm 0.0009 f$ or $S_{3}, 2.00533 \pm 0.001$ for $S_{4}, 1.9932 \pm 0.0022$ for $S_{5}$ and $1.9847 \pm 0.001$ for $S_{6}$. The spectral line width $=90.7$ gauess. $S_{3}$ with the magnetic field 3459.18 gauss was chosen to perform all the work in this study due to its high sensitivity.

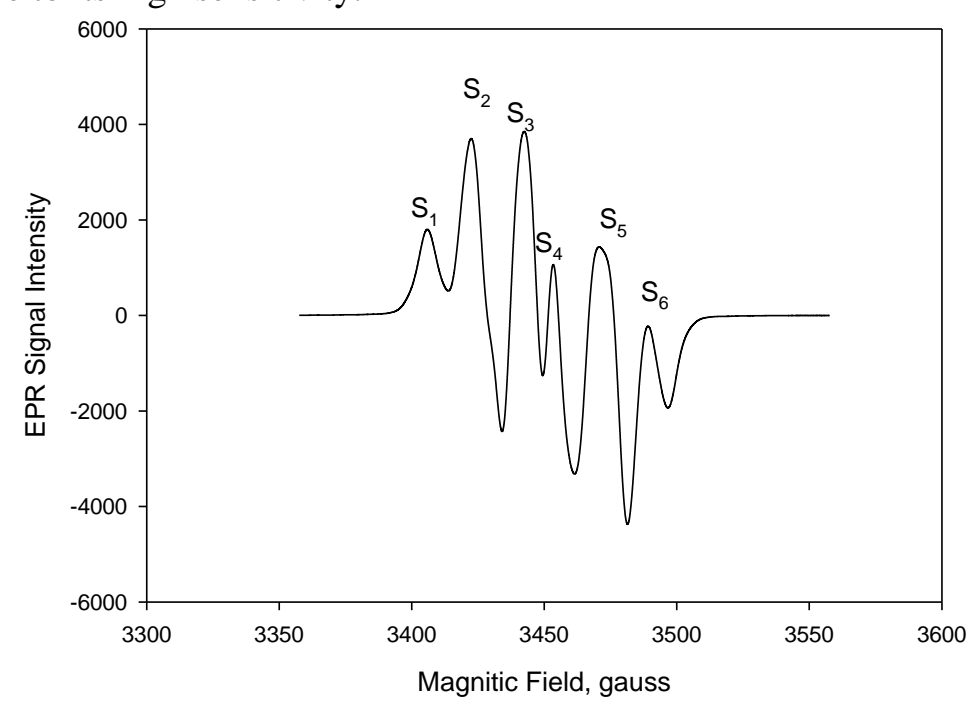

Fig. 2. EPR spectrum of irradiated mono sodium glutamate powder irradiated at $90 \mathrm{kGy}$.

Power dependence

Fig. 3. shows the microwave power dependence of the mono sodium glutamate signal intensity. The intensity of EPR signals increases in proportion to $\mathrm{p}^{1 / 2}$ up to high microwave power. Appropriate setting of power level is necessary for the EPR measurements. The signal intensity increases as a function of power up to $0.7969 \mathrm{mw}$ without reaching saturation.

Egypt. J. Rad. Sci. Applic., Vol. 27, No. 1-2 (2014) 


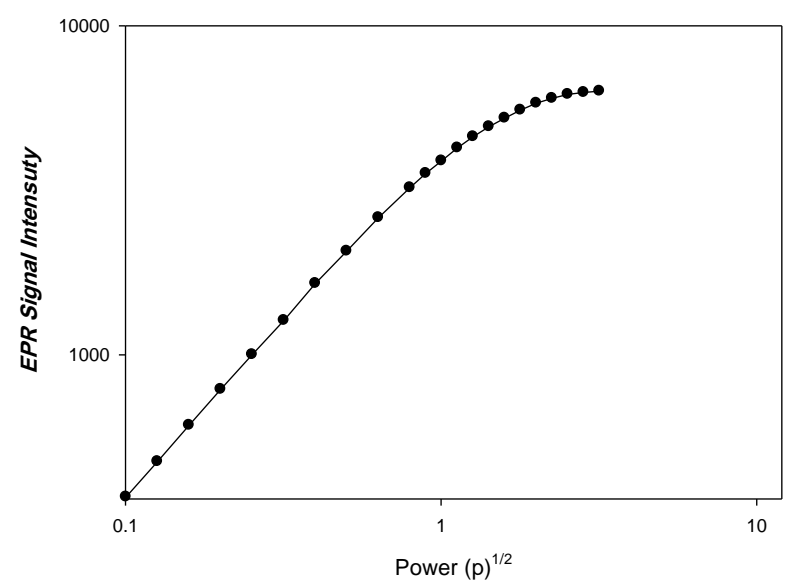

Fig. 3. Relationship between square root of microwave power (mw 1/2) and EPR signal intensity of gamma irradiated mono sodium glutamate.

Effect of gamma radiation on mono sodium glutamate powder

Fig. 4. represents the spectra of unirradiated and irradiated mono sodium glutamate. The powder wt is $0.1286 \mathrm{~g}$ and irradiated doses are 8, 20, 45, 70, 90 kGy. From the figure it is clear that the signal intensity increases with the increase of irradiation dose without any change in its shape.

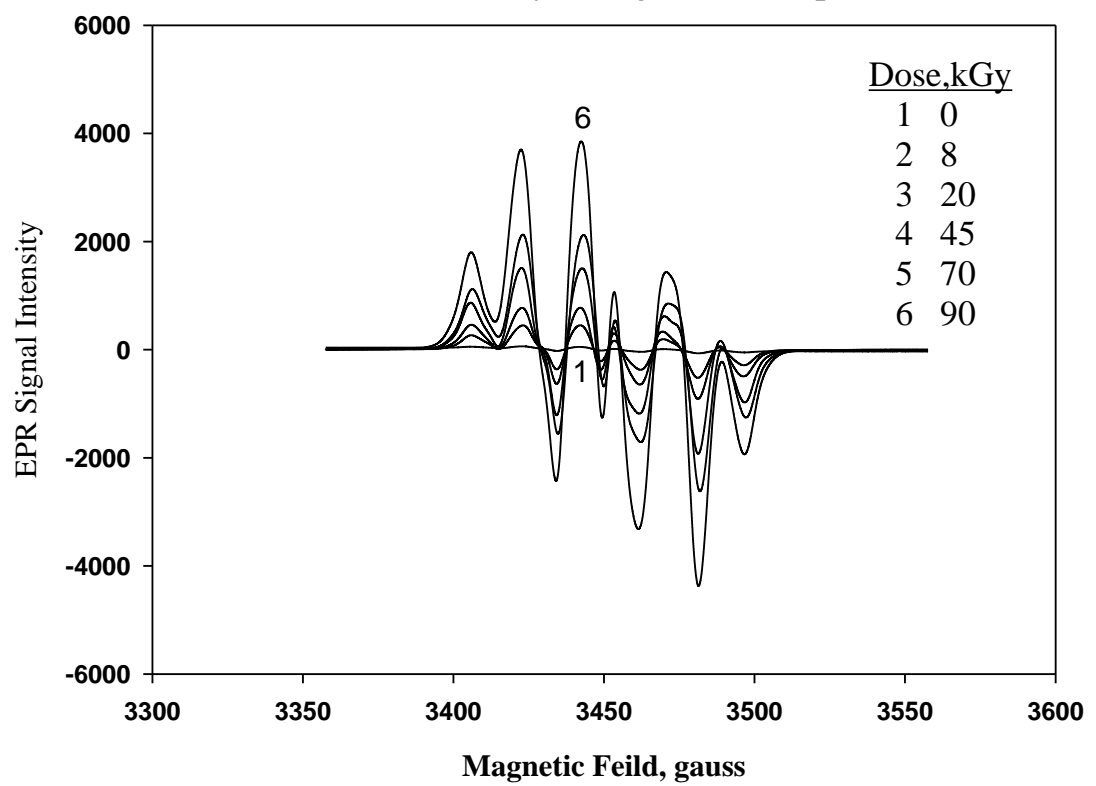

Fig. 4. ESR spectra of mono sodium glutamate powder at different doses.

Egypt. J. Rad. Sci. Applic., Vol. 27, No. 1-2 (2014) 
It can be seen that no signal has detected for the unirradiated mono sodium glutamate. As we know, when ionizing radiation passes through a material it impart some of its energy to that material. The imparted energy may be high enough to cause a break in bonds inside the molecules or between molecules or both, in such cases, free radicals are created. Behaviour of radiation induced radicals may lead to further understanding of molecular interactions or molecular (radicals) dynamics, or may lead to a decision on the preference of a material for a specific applied from a dosimetric point of view. Also organic radicals are characteristic by large line- width which due to super-hyperfine interaction with nearby protons in neighbouring molecules (Lendzian, 2005).

Fig. 5. represents the response curve of mono sodium glutamate powder in terms of peak to peak amplitude normalized to dosimeter mass (peak high/ mass) versus the absorbed dose. It can be seen that the radiation sensitivity of the mono sodium glutamate increases with the increase of the absorbed dose. This attributed to the increase in number of free radicals induced by radiation.

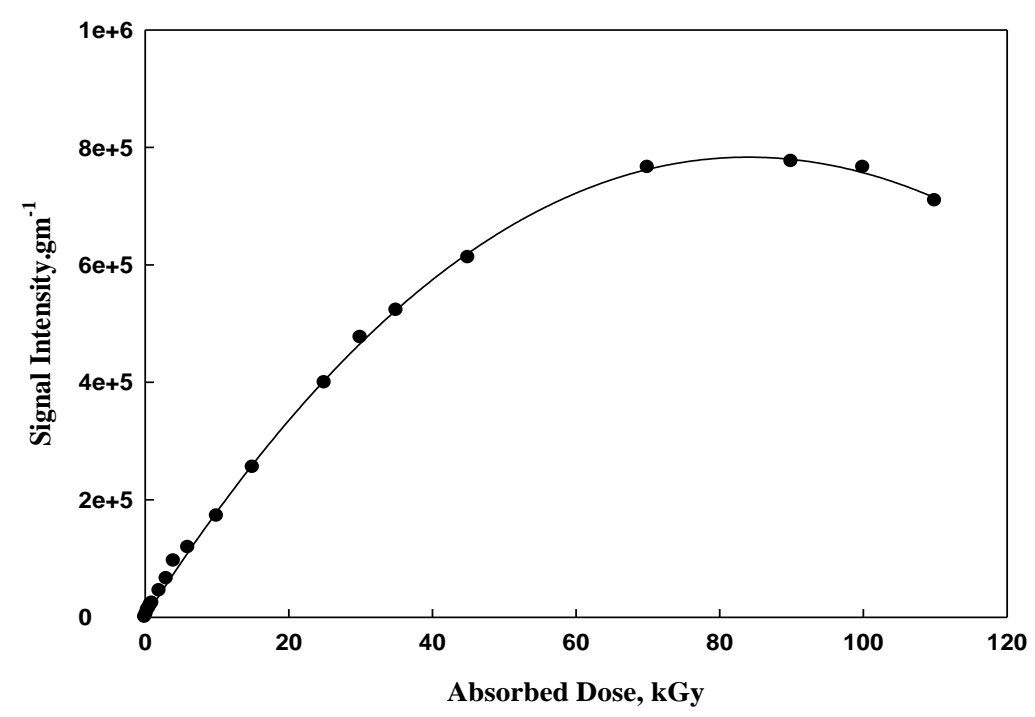

Fig. 5. Response curve of mono sodium glutamate powder at different doses.

\section{Short term decay of mono sodium glutamate powder}

$0.0813 \mathrm{~g}$ of mono sodium glutamate powder was irradiated to a dose of 5 kGy and fixed in cavity centre and measure for $5 \mathrm{~h}$. Fig. 6 . shows the obtained fading behaviour of the EPR signal. It can be seen that the free radicals

Egypt. J. Rad. Sci. Applic., Vol. 27, No. 1-2 (2014) 
undergoes random orientation during the first $30 \mathrm{~min}$ then tend to be stable after losing their extra energy until the end of the storage period.

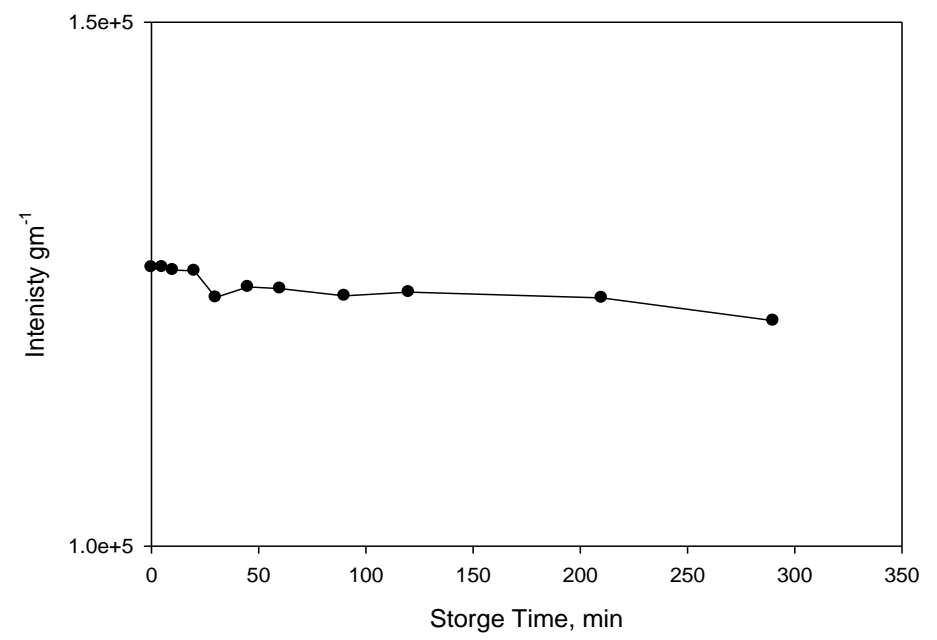

Fig. 6. Decay of EPR line of irradiated mono sodium glutamate powder at a dose $5 \mathrm{kGy}$.

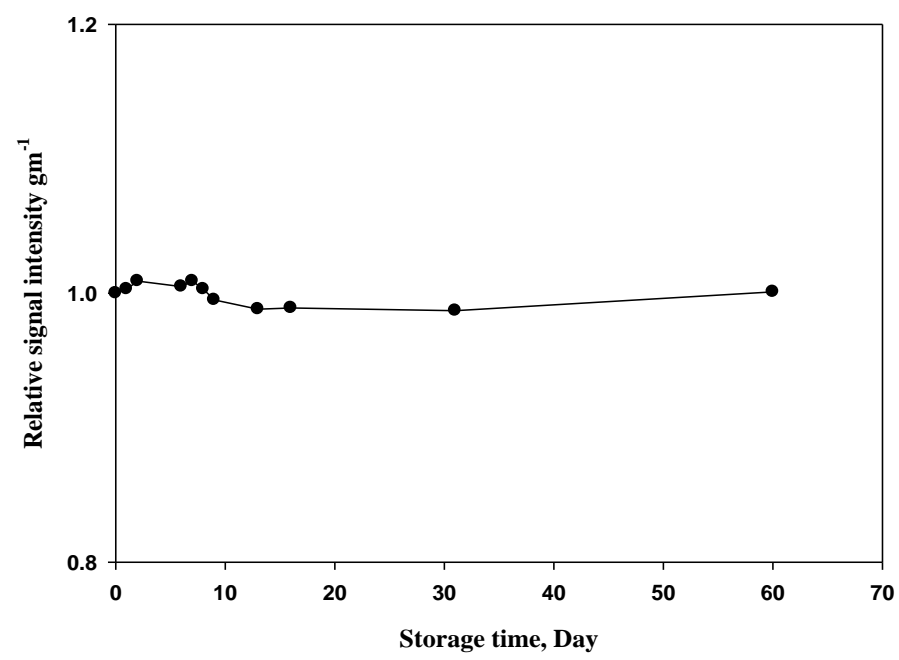

Fig. 7. Post-irradiation stability of mono sodium glutamate powder to $25 \mathrm{kGy}$.

\section{Post irradiation stability of mono sodium glutamate powder}

$0.1287 \mathrm{~g}$ mono sodium glutamate was irradiated to a dose of $25 \mathrm{kGy}$ and measures the signal intensity at different time intervals of 60 days as in Fig. 7. The peak intensity value shows slight increase in the first 10 days and then tends to be stable to the end of the storage period. 


\section{Radiation sensitivity}

The efficiency of a dosimeter is expressed by a G-value i.e., the number of radicals or ions produced by the absorbed radiation per $100 \mathrm{ev}$. The radical formation efficiency was determined by double integration of the first derivative spectra of DPPH and compared with those of irradiated materials. The absolute spin concentration was estimated according to Hassan et al. (2000) and Ikeya (1985) by using the following equation:-

$$
\mathrm{n}=\frac{A_{\text {sample }} \times^{\mathrm{n}_{\text {strong pitch }}}}{A_{\text {strong pitch }} \times \operatorname{Dose}(\mathrm{Gy}) \mathrm{x} \mathrm{m}(\mathrm{g})}=6.25 \times 10^{13} \cdot \mathrm{G}\left(\mathrm{Gy}^{-1} \mathrm{~g}^{-1}\right)
$$

where, $\mathrm{A}_{\text {sample, }} \mathrm{A}_{\text {strong pitch }} \pi_{\text {strong pich }}$ and $\mathrm{m}$ are the areas of integrated signals of sample and strong pich, number of spin in strong pitch, number of spin in strong pitch and the mass of sample, respectively. The G-value of the whole area was found to be $0.2019 \pm 0.01$.

\section{Effect of gamma radiation on mono sodium glutamate rods}

Four different concentrations of mono sodium glutamate namely 5, 10, 20, $40 \%$ irradiated to a dose of $40 \mathrm{kGy}$ were shown in Fig. 8. from which it could be concluded that the peak intensity increases with the increase of mono sodium glutamate in the rods.

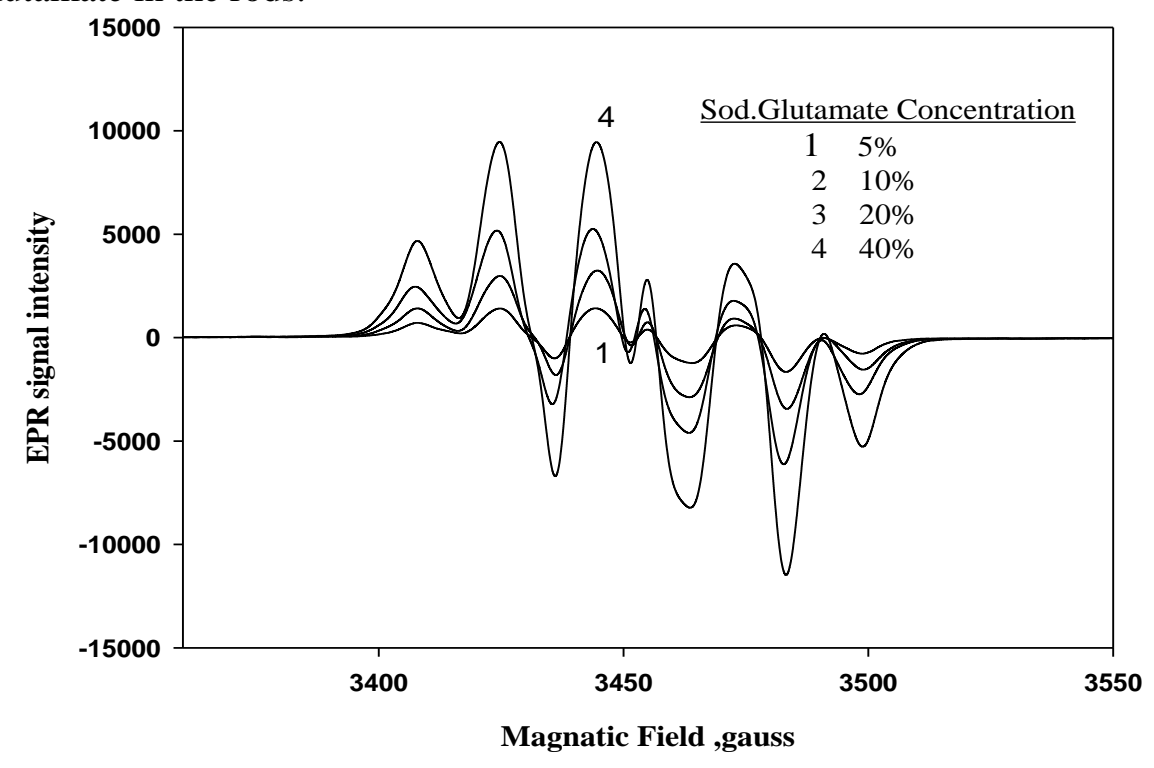

Fig. 8. EPR spectra recorded for mono sodium glutamate rods of different concentrations irradiated to a dose of $40 \mathrm{kGy}$.

Egypt. J. Rad. Sci. Applic., Vol. 27, No. 1-2 (2014) 


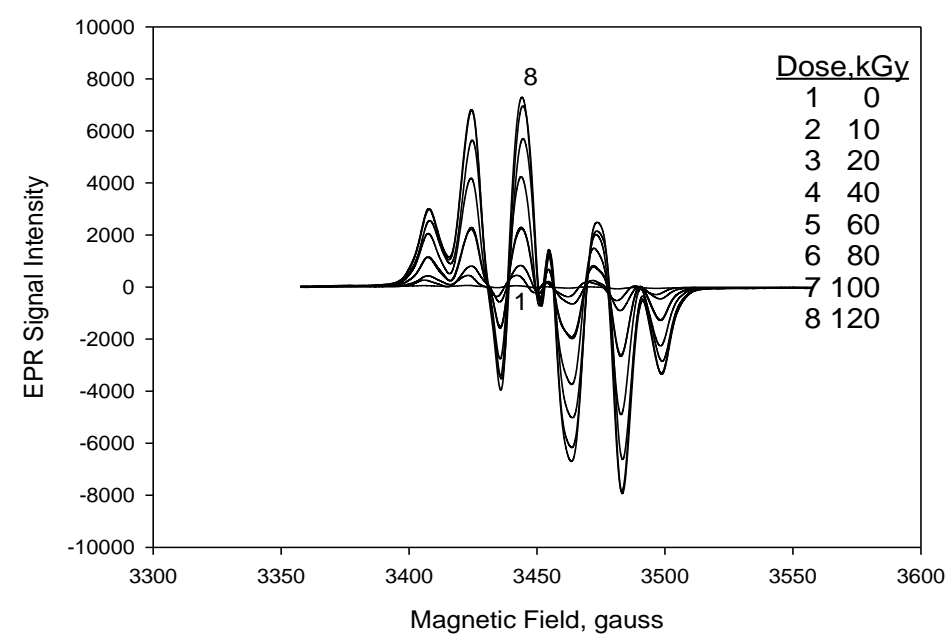

Fig. 9. EPR spectra of mono sodium glutamate $(20 \%)$ irradiated to $10,20,40,60$, 80, 100 and $120 \mathrm{kGy}$.

Fig.9. represents the EPR spectra of unirradiated and irradiated mono sodium glutamate rods (20\%) were recorded at a series of absorbed doses 10 , 20, 40, 60, 80, 100, $120 \mathrm{kGy}$. From the Fig. 9. it can be seen that the EPR signal begins to develop upon irradiation and its amplitude increases with increasing absorbed dose of gamma ray photons without any change in its shape.

\section{Dose Response of Rods with different concentration of mono sodium glutamate}

Fig. 10. represents the response curves of 4 sets of mono sodium glutamate $(5,10,20,40 \%)$ to different absorbed dose range from 5-120 kGy.

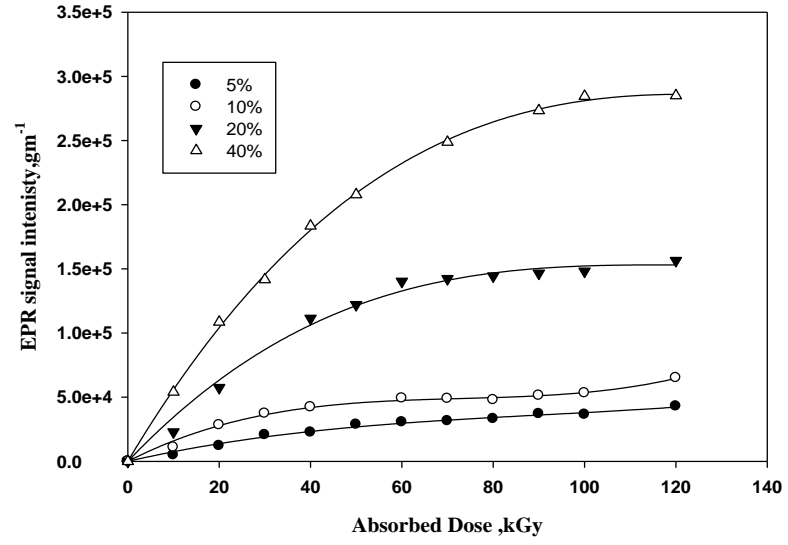

Fig. 10. Dose response curve of irradiated different concentration of mono sodium glutamate rods.

Egypt. J. Rad. Sci. Applic., Vol. 27, No. 1-2 (2014) 
The response curves obtained for the irradiated sample in terms of average peak to peak amplitude normalized to dosimeter mass (peak high/ mass) versus the absorbed dose. It can be seen that the radiation sensitivity increases with the increase of mono sodium glutamate in the rods. This increase is attributed to the increase of the free radicals induced by radiation.

\section{Post-irradiation stability at different storage conditions}

The EPR signal stability has been studied for three sets of mono sodium glutamate rods $(20 \%)$ stored at different conditions (dark, light, and at $40{ }^{\circ} \mathrm{C}$ ). The stability was investigated as a relative to that value immediately after irradiation as shown in Fig. 11. The signal intensity decreases at the beginning of storage time then tends to be stable at the end.

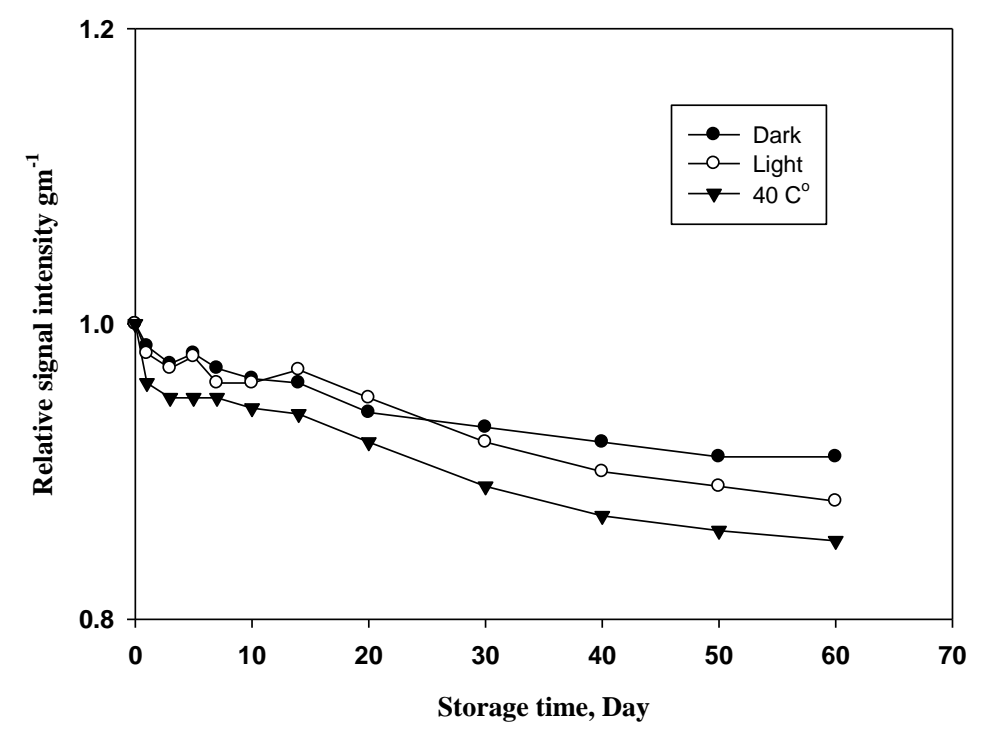

Fig. 11. Relative peak to peak signal light as a function of storage time at different storage conditions (concentration $20 \%$, dose $25 \mathrm{kGy}$ ).

\section{Humidity during irradiation}

The effect of relative humidity during irradiation on the response of mono sodium glutamate of $20 \%$ concentration was investigated by the irradiation of the rods to $25 \mathrm{kGy}$ at different humidity values(0-95\%). To establish the RH levels, the rods were suspended over various saturated salt solutions in tightly closed vials (Wexler and Hasegawa, 1954). The rods were stored before 
irradiation at room temperature for a period of $72 \mathrm{~h}$ to maintain equilibrium moisture content in the rod during irradiation. Fig. 12. shows the variation of the EPR intensity as a function of relative humidity during irradiation relative to the response value at $33 \%$ relative humidity. It can be concluding that mono sodium glutamate rods have negligible humidity effect not exceed $5 \%$ in the range of humidity from0-100\%

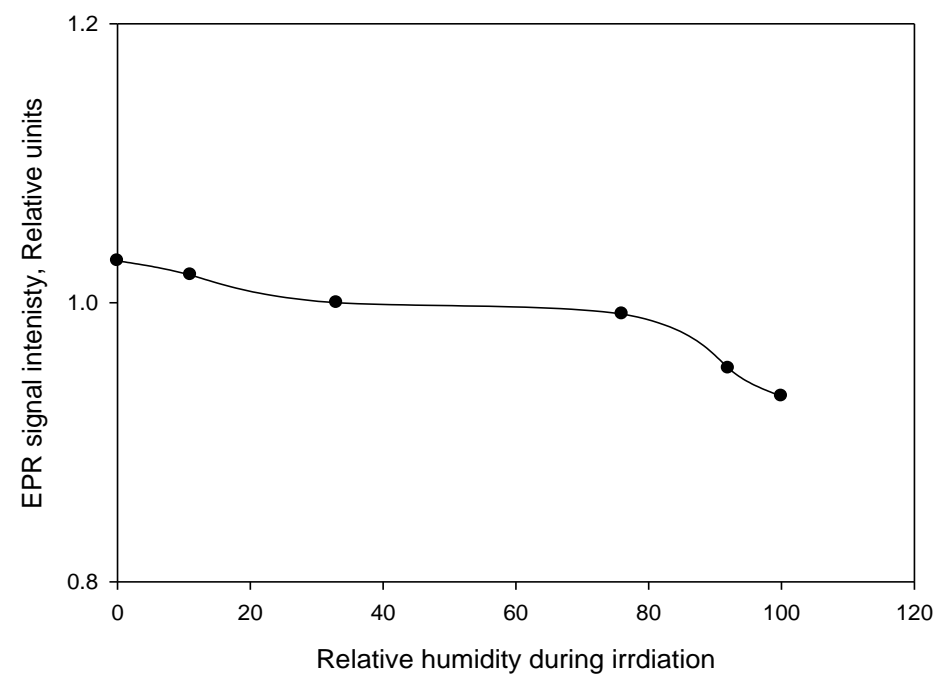

Fig. 12. Variation of the EPR response of mono sodium glutamate rods (conc. $20 \%$ ) as the function of relative humidity during irradiation (Absorb dose $=25 \mathrm{kGy}$ ).

\section{Conclusion}

From the presented data of the study, the following conclusion can be drawn: Mono sodium glutamate powder is a suitable dosimeter to a dose range 0-90 kGy while mono sodium glutamate rods are 5-120 kGy. The dosimetric characteristic of rods containing different concentrations of mono sodium glutamate was recorded. The rods have significant EPR signal which develops upon irradiation and intensity of the signal increases upon the increase in irradiation dose. These rod dosimeters have insignificant dependence on the change of relative humidity during irradiation. It is recommended to calibrate these dosimeters at conditions of use of humidity value less than $60 \%$. The properties of the prepared mono sodium glutamate rods suggest their useful application for food irradiation, medical and industrial application. This 
dosimeters are fairly stable before and after irradiation and show little fading between $5-10 \%$ over 60 days storage period.

\section{References}

Abdel-Fattah, A. A., Eel-Din. H. and Abed-Rehim F. (2004) New alanine/ EPR dosimeter using EVA copolymer/ paraffin as a binder for high-dose radiation dosimtry: performance characterization. Int. J. Polym. Mater., 53, 927.

Bermann, F., De Choudens, H. and Descours, S. (1970) In Advances in Physical and Biological Radiation Detector, Proc. Symp. Vienna, IAEA Publication STI/PUB/269 (Vienna, International Atomic Energy Agency) p. 311.

Beshir, W. B., Abedel-Fattah, A. A., Abedel-Rehim, F. and Hassan, H. M. (2012) EPR dosimetric properties of radiation-Formed radicals in arginine mono hydrochloride. J. Potochem. Photobiol., 116, 1.

Bradshaw, W. W., Cadena, D. G., Crawford, E. W. and Spetzler, H. A. W. (1962) The use of Alanine as a solid dosimeter. Radiat. Res., 17, 11.

Gancheva, V., Sagstuen, E., and Yordonov, N. D. (2006) Study on the EPR/ dosimetric properties some substituted alanine. Radiat. Phys. chem., 75, 329.

Hassan, G. M. and Ikeya, M. (1997) Radical formation of lithium lactate for ESR dosimetry. J. Nucl. Sci. Technol., 34, 1185.

Hassan, G. M., Ikeya, M. and Toyoda, S. (1998) Lithium lactate as an ESR dosimeter. Appl. Radiat. Isotop., 49, 823.

Hassan, G. M., Ulku, W. and Ikeya, M. (2000) Radical Formation in Lithium and magnesium oxalate. Jap. J. Appl. Phys., 39, 6236.

Ikeya, M. (1985) Techniques of Radiation Dosimetry Electron Spin Resonance. In: Mahesh, K., Viji, D.R. Wileyb eastern, New Delhi, Chap. 15.

Ikeya, M. (1993) New Applications of electron spin resonance-dating, dosimetry and microscopy. World Scientific, Singapare, p.395.

Lendzin, F. (2005) Structure and interactions of amino acid radicals in class 1 ribonucleotide reductase studied by ENDOR and high-field EPR spectroscopy. Biochim. Biophys. Acta, 170, 67.

Nakajima, T. (1988) Sugar as emergency populace dosimeter for radiation accident. Heal. Phys., 55, 951.

Nakajima, T. (1995) ESR of sugar as personal monitor for radiation emergencies. Appl. Radiat. Isotop., 46, 819.

Nakajima, T. and Ohtsuki, T. (1990) Dodimetry for radiation emergencies: radiation induced free radicals in sugar of various countries and effect of pulverizing on the ESR signal. Appl. Radiat. Isotop., 41, 359.

Regulla, D. F. and Deffner, U. (1983) System transfer dosimetry in radiation processing. Radiat. Phys. Chem., 22, 305.

Egypt. J. Rad. Sci. Applic., Vol. 27, No. 1-2 (2014) 
Regulla, D. F. and Deffner, U. A. (1982) dosimetry by ESR spectroscopy of alanine. Int. J. Appl. Radiat. Isotop., 33, 1101.

Rocha, M. V., Carvalho, H. W., Lacerda, L. C., Simoes, deSouza, G. G. and Ramalho, T. C. (2014) Ionic desorption in PMMA-gamma-Fe2O3 hybrid materials induced by fast electrons: an experimental and theoretical investigation. Spectrochim. Acta A Mol. Biomol. Spectrosc., 117, 276.

Talbi, S., Raffi, J., Arena, S., Colombani, J., Piccerelle, P., Prinderre, P. and Dolo, J. M. (2004) EPR study of gamma induced radicals in amino acid powders. Spectrochimica Acta, part A, 60, 1335.

Wexler, A. and Hasegawa, S. (1954) Relative humidity-temperature relationships of some saturated salt solutions in the temperature $0^{\circ} \mathrm{C}$ to $50^{\circ} \mathrm{C}$. J. Res. NBS, $\mathbf{5 3}$, 1920.

(Received: 01/06/2014;

accepted: 17/07/2014) 


$$
\begin{aligned}
& \text { اسـتخدام الصــوديوم جلوتامــات كمقيـاس للجرعـهـ الاشـعاعية } \\
& \text { باستخدام الرنين المغناطيسى المغزلى جلى } \\
& \text { سيده عيد و سيف الدين ابراهيم و عصماء صبحى }
\end{aligned}
$$

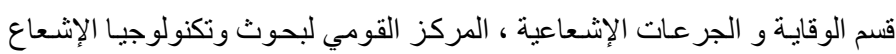

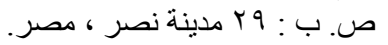

\footnotetext{
تم فى هذا البحث در اسة استخدام مادة الصوديوم جلوتامات على شكل

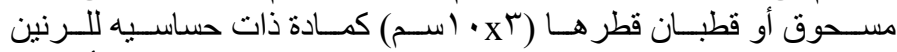

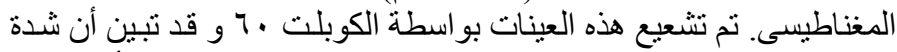

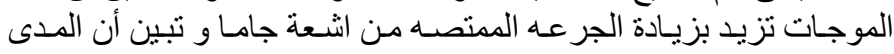

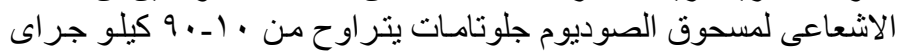

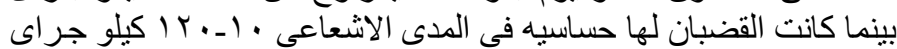

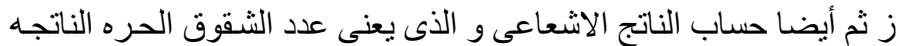

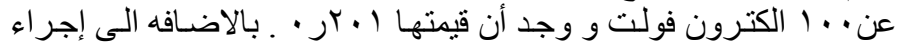

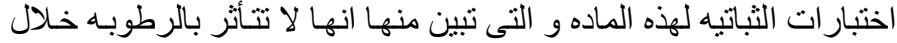
التتعيع و أيضا تتمتع بثباتيه عاليه قبل و بعد التشعيع.
}

Egypt. J. Rad. Sci. Applic., Vol. 27, No. 1-2 (2014) 